\title{
Urban metabolism in Syracuse, NY - introduction
}

\author{
David J. Nowak ${ }^{1}$
}

Published online: 8 December 2016

(C) Springer Science+Business Media New York (outside the USA) 2016

This special issue of Urban Ecosystems contains a series of papers related to assessing urban metabolism in Syracuse, NY. These papers were developed under the Urban Long-Term Research Area Exploratory Awards Program funded by the National Science Foundation. Objectives of this two-year project (2009-2011) in Syracuse, NY were to investigate: a) changes in urban metabolism and the urban forest ecosystem, b) spatial and temporal dynamics related to water and air quality, and c) how human preferences can influence green infrastructure implementation and outcomes.

From a historical perspective, energy metabolism (respiration) in Syracuse became increasingly centralized in the urban core between 1840 and 1950, and has since become more diffused. The ratio of city respiration to net primary production in the county exceeded 1:1 by 1860. After a period of intensive industrialization and land use conversion from forests to farms, the respiration to production ratio reached a maximum of 9:1 in 1930. Increased forest cover and improved agricultural yields, along with declining urban population and deindustrialization, reduced this ratio to just under 2:1 by the 2000s. Achieving lower respiration to production ratios require either increased local production of food and fuels or decreased per capita energy consumption (Balogh et al.).

Currently, the urban forest in Syracuse provides about \$2.4 million dollars per year in ecosystem services of carbon sequestration, air pollution removal and reduced building energy use. Urban forest structure and functions have changed in recent years with tree cover and total tree population declining in the late 1990s to early 2000s and then increasing again by 2009. Most of this change was likely precipitated by a major storm in the late 1990s and limited development that facilitated natural regeneration. This regeneration is altering the structure of the forest as many invasive and pioneer species are dominating the regeneration. This change in structure will have an impact on future ecosystem services derived from the urban forest (Nowak et al.)

In comparing carbon dioxide $\left(\mathrm{CO}_{2}\right)$ flux between a downtown site and a residential site, $\mathrm{CO}_{2}$ fluxes were strongly influenced by surrounding land use, particularly impervious surfaces, vegetation and traffic volume. The downtown site had relatively constant positive fluxes due to vehicular traffic, while the residential site was dominated by vegetation influences in the

David J. Nowak

dnowak@fs.fed.us 
leaf-on period, producing maximum negative fluxes (sinks) around mid-day. Understanding these variable source-sink relationships in urban areas have important implications for $\mathrm{CO}_{2}$ budgets, carbon cycles and climate modeling (Buckley et al.)

Measurements of dissolved oxygen, temperature, conductivity and turbidity in streams in the Syracuse area revealed a "Jekyll-Hyde" analogy. Under dry conditions, the streams behaved like a headwater stream, but during storms, the streams had greater discharge and rapid swings in oxygen, temperature, conductivity and turbidity. These dynamics could be dampened by increasing soft, absorbent surfaces (green infrastructure) in the city (Limburg et al.).

Investigation of resident receptivity and preferences toward green infrastructure implementation in Syracuse revealed that a "government participation" scenario of tree planting on street parking strips and a "household participation" scenario that put rain barrels and rain gardens in randomly selected private residential lots would contribute to a modest reduction in storm water peak flow and total runoff volume across a sewershed. These results support sustainable storm water management planning that addresses citizen preferences and needs (Sun and Hall).

People, vegetation and the local environment are landscape features that interact across a region and affect each other. Understanding the interactions between people and nature in cities can lead to improved management to reduce energy use, increase local production of food and fuels, improve water and air quality, and consequently human health and well-being within cities. 